\title{
High temperature tensile properties and deep drawing of fully green composites
}

\author{
R. Nakamura ${ }^{*}$, K. Goda², J. Noda², J. Ohgi ${ }^{3}$ \\ ${ }^{1}$ GraduateSchool of Science and Engineering, Yamaguchi University, Tokiwadai, Ube, Yamaguchi 755-8611, Japan \\ ${ }^{2}$ Department of Mechanical Engineering, Yamaguchi University, Tokiwadai, Ube, Yamaguchi 755-8611, Japan \\ ${ }^{3}$ Department of Applied Medical Engineering Science, Yamaguchi University, Tokiwadai, Ube, Yamaguchi 755-8611, \\ Japan
}

Received 15 October 2008; accepted in revised form 5 December 2008

\begin{abstract}
In recent years, research and development of materials using biomass sources are much expected to construct a sustainable society. The so-called green composite consisting of natural fibers and biodegradable resin, is one of the most promising materials in developing biomass products. In this study, especially, we focus on the tensile deformation behavior of the green composites reinforced with ramie woven fabrics at high temperature. The results show that the fracture strain at high temperatures increases larger than that of room temperature, and initial deformation resistance of the composites seen at room temperature does not appear at high temperatures. Thus, several conditions to cause more deformability of the green composites were found. Finally, in order to utilize such deformability, Lankford-values of the green composites were clarified, and deep drawing was carried out for sheet materials made of the green composites.
\end{abstract}

Keywords: polymer composites, green composite, natural fiber, deep drawing, tensile strength

\section{Introduction}

Development of materials technology using biomass is anticipated for creation of a sustainable society. Especially, composites consisting of plantbased natural fibers and biodegradable resin, socalled fully green composites, are highly anticipated for practical use [1,2]. Advantages of natural fibers include their excellent specific strength and stiffness properties, low cost, and low density. They are more abundant in nature and more ecofriendly in contrast to conventionally used glass and fossil-fuel-based fibers. Consequently, many studies examining the mechanical and interfacial properties of natural fiber reinforced composites have been carried out [3-5]. To date, kenaf-fiberreinforced polylactic acid (PLA) matrix composites have been used for spare tire covers [6], circuit boards [7], and so on, of which the processing is based on injection molding. The merit of this technique is known to be generation of near-net shape products, even if they have a complex shape. However, the reinforcing natural fibers are broken and shortened during extrusion and/or injection molding processes. Consequently, the strength and stiffness of the fibers are not well reflected in the resultant mechanical properties of the products. Therefore, we specifically investigated green composites reinforced with woven fabrics of ramie fiber yarns and examined their deformation behavior [8]: the composites can be extended somewhat through yarn twisting and crimps of fabrics, and can be extended much more through mercerization $[8,9]$. If such properties could be used effectively, green composites using woven fabrics might be a

*Corresponding author, e-mail: j006wc@yamaguchi-u.ac.jp

(c) BME-PT and GTE 
new plastic processing product that is mechanically superior to conventional polymer products.

The purpose of this study is to explore if the green composites can be applied for plastic processing. First, high-temperature tensile properties and the Lankford-value [10] ( $r$-value) of the composites were explored. Then, deep drawing of the composite laminates was carried out.

\section{Experimental procedure}

\subsection{Materials}

A woven ramie fabric (No.25, single yarn, 44 warp /inch, 46 weft/inch) supplied from TOSCO Co. Ltd., Japan was used as a reinforcement material. The fabric surface is shown in Figure 1. Physical characteristics of ramie fibers are shown in Table 1. The resin used in this study is a biodegradable resin (Ecoflex; BASF Japan Ltd.) that was originally shaped as a pellet. A $2 \mathrm{~mm}$ thick sheet of this resin was preliminarily prepared through compression molding, and was used as a matrix material. Density and mechanical properties of the resin are shown in Table 2.

\subsection{Fabrication method}

Green composites were fabricated using a hot-press machine (mini Test Press-10; Toyo Seiki Seisaku

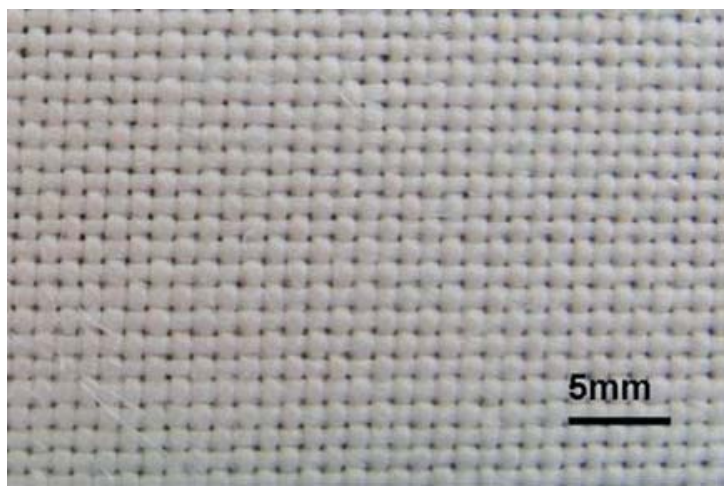

Figure 1. Ramie woven fabric
Sho Ltd., Japan). Three fabrics of $220 \times 220 \mathrm{~mm}^{2}$ size were overlapped with one resin sheet of the same size. We used two kinds of stacking sequence as $0-90 \%-90^{\circ} / 0-90^{\circ}$ (UT) and $\pm 45^{\circ} / \pm 45^{\circ} / \pm 45^{\circ}$ (UT-45).One set of these constituents was pressed with $9.8 \mathrm{MPa}$ at $170^{\circ} \mathrm{C}$ for $5 \mathrm{~min}$. Then they were cooled down to room temperature with the same pressure. Cross sectional optical micrograph of a composite used in this study is shown in Figure 2. Tensile specimens were cut off from the fabricated composite laminates. The shape and dimension of the tensile specimens are shown in Figure 2. Hereinafter, this composite laminate is denoted as UT composite. In addition, the composite laminates reinforced with alkali-treated woven fabrics were tensile-tested in identical fabrication conditions. To make ductility, alkali treatment using a high concentration sodium hydroxide solution was performed $[11,12]$. In this case, the ramie woven fabrics were alkali-treated in advance in $21.5 \mathrm{wt} \%$ sodium hydroxide solution for two hours. And then they were washed in water including a small quantity of acetic acid. Hereinafter, this composite laminate is denoted as AT composite. Fiber volume fractions of UT and AT composites fabricated in this study were in the range of 44 to $52 \%$.

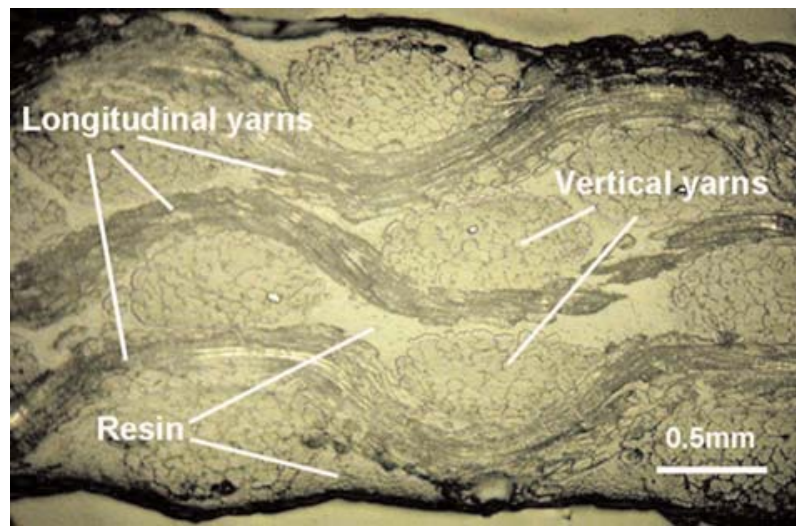

Figure 2. Optical micrograph of the longitudinal crosssection of a green composite reinforced with untreated ramie woven fabrics

Table 1. Properties of ramie fibers

\begin{tabular}{|c|c|c|c|c|c|c|c|}
\hline $\begin{array}{c}\text { Density } \\
{\left[\mathbf{M g} / \mathbf{m}^{3}\right]}\end{array}$ & $\begin{array}{c}\text { Cellulose } \\
{[\mathbf{w t} \%]}\end{array}$ & $\begin{array}{c}\text { Lignin } \\
{[\mathbf{w t} \%]}\end{array}$ & $\begin{array}{c}\text { Hemicellulose } \\
{[\mathbf{w t} \%]}\end{array}$ & $\begin{array}{c}\text { Pectin } \\
{[\mathbf{w t} \%]}\end{array}$ & $\begin{array}{c}\text { Wax } \\
{[\mathbf{w t} \%]}\end{array}$ & $\begin{array}{c}\text { Microfibrillar angle } \\
{\left[{ }^{\circ}\right]}\end{array}$ & $\begin{array}{c}\text { Moisture content } \\
{[\mathbf{w t} \%]}\end{array}$ \\
\hline 1.50 & $68.6-76.2$ & $0.6-0.7$ & $13.1-16.7$ & 1.9 & 0.3 & 7.5 & 8.0 \\
\hline
\end{tabular}

Table 2. Mechanical properties of the biodegradable resin (Eco-flex)

\begin{tabular}{|c|c|c|c|c|}
\hline $\begin{array}{c}\text { Density } \\
{\left[\mathbf{M g} / \mathbf{m}^{3}\right]}\end{array}$ & $\begin{array}{c}\text { Melting point } \\
{\left[{ }^{\circ} \mathbf{C}\right]}\end{array}$ & $\begin{array}{c}\text { Tensile Strength* } \\
{[\mathbf{M P a}]}\end{array}$ & $\begin{array}{c}\text { Fracture Strain* } \\
{[\%]}\end{array}$ & $\begin{array}{c}\text { Young's modulus* }^{*} \\
{[\mathbf{G P a}]}\end{array}$ \\
\hline $1.25-1.27$ & $105-115$ & 19.8 & 197.2 & 0.14 \\
\hline
\end{tabular}

*value of the properties is obtained in the tensile test 


\subsection{Tensile test}

Tensile tests of composite laminates were carried out along their weft directions at room temperature at the crosshead speed of $0.5 \mathrm{~mm} / \mathrm{min}$ using an Instron-type testing machine (Autograph IS-5000; Shimadzu Corp.); they were also carried out at 100, 115 or $130^{\circ} \mathrm{C}$ at $1.5 \mathrm{~mm} / \mathrm{min}$ using a hydraulic testing machine (Servo-pulser EHF-EB10; Shimadzu Corp.). In the latter case, the specimen was tensiletested $10 \mathrm{~min}$ after fixing the specimen in the electronic furnace of the machine. The number of tensile specimens shown in Figure 3. was 4-6 for each condition. In addition, to explore the plastic anisotropy of the composite laminates, their $r$-values were investigated at $115^{\circ} \mathrm{C}$ in the conditions described above.

The $r$-value expresses a measure of the plastic anisotropy of a sheet material and is often used for evaluating the quality of deep drawing products. Lankford et al. proposed this idea in 1950 [10] and nowadays it is used widely in the field of metal rolling process. A schematic of strain states during deep drawing is shown in Figure 4. The $r$-value is defined as a ratio of the true strain in the width direction, $\varepsilon_{w}$, to the true strain, $\varepsilon_{t}$, in the thickness direction, when a sheet material is pulled in uniaxial tension beyond its elastic limit, as follows in Equation (1):

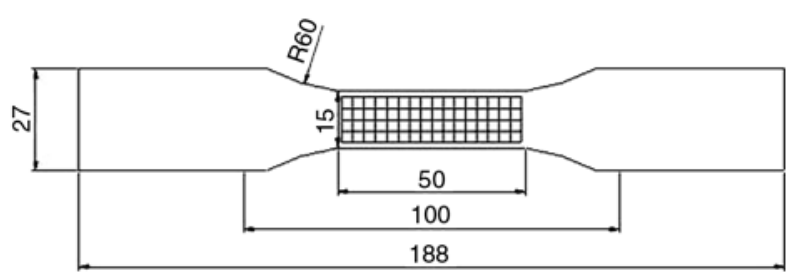

Figure 3. Shapes and dimensions of the tensile specimen

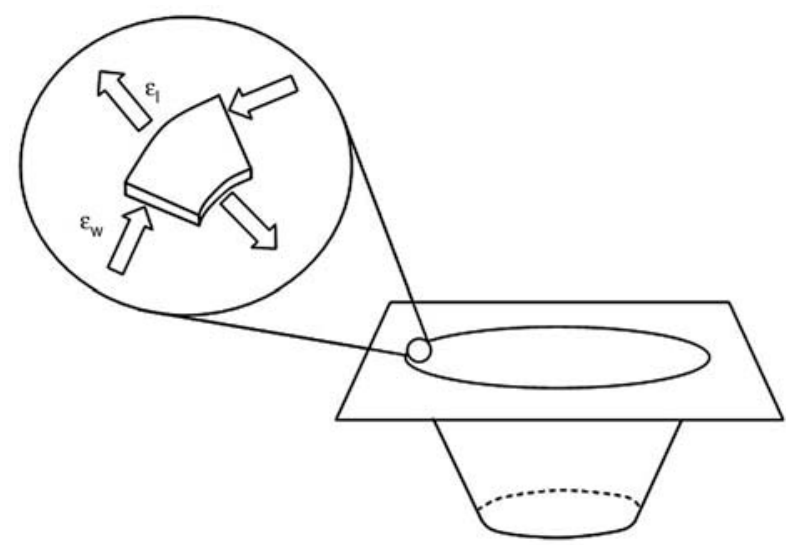

Figure 4. Schematic of strain states during deep drawing

$$
r \equiv \frac{\varepsilon_{w}}{\varepsilon_{t}}
$$

where $\varepsilon_{w}=\ln (w / W), \varepsilon_{t}=\ln (t / T), w$ and $t$ are final width and thickness of the material, respectively. $W$ and $T$ are initial values of $w$ and $t$. The $r$-value means an index of deep drawing, and higher $r$-value yields more deeply drawn products. In general it is difficult to measure precisely change of the thickness of thin plate specimens. Therefore, the $r$-value is estimated as Equation (3), by changing $\varepsilon_{t}$ as Equation (2):

$\varepsilon_{t}=\left(\varepsilon_{l}+\varepsilon_{w}\right)$

$$
r=-\frac{\varepsilon_{w}}{\varepsilon_{l}+\varepsilon_{w}}=-\frac{\ln \frac{w}{W}}{\ln \frac{l}{L}+\ln \frac{w}{W}}
$$

Equation (2) follows the law of volume constant. To check the degree of degradation of ramie fibers at high temperatures, single fiber tensile tests were also carried out at room temperature, and at 100 , 130,160 , and $200^{\circ} \mathrm{C}$ at the speed of $2.0 \mathrm{~mm} / \mathrm{min}$. Single ramie fibers were extracted carefully from a ramie sliver (Tosco Co. Ltd., Japan). The tensile testing machine used here was a hand-made testing machine, to which a fine capacity load-cell and hand-made small electrical furnace was attached. The tensile testing method for single fibers follows the Japanese Industrial Standard (JIS R 7606; Carbon fibre determination of the tensile properties of the single-filament specimens). The gage length of the tensile specimen was $20 \mathrm{~mm}$. The number of single fiber specimens was 20-25 for each condition.

\subsection{Deep drawing}

Deep drawing processing was applied to composite laminates using a hotplate-attached press machine (20 t capacity; Yamamoto Suiatsu Kogyosho Co. Ltd.). In this experiment, the composite laminate described earlier was first cut out to $220 \times 220 \mathrm{~mm}^{2}$. Next, the laminate was fixed on a square metal frame, in which a hole of $70 \mathrm{~mm}$ diameter was provided at the center. The composite laminate was heated in an electrical furnace of $130^{\circ} \mathrm{C}$ for $10 \mathrm{~min}$. In this condition, we found from an infrared ther- 
mometer that the surface temperature of the composite laminates achieved $115^{\circ} \mathrm{C}$. Furthermore, the composite laminate was shifted promptly to the press machine and drawn at the depth of 10 or $20 \mathrm{~mm}$ using a $50 \mathrm{~mm}$ diameter cylindrical punch or a $50 \times 50 \mathrm{~mm}^{2}$ square punch.

\section{Results and discussion}

\subsection{Tensile properties of fully green composite laminates and natural fibers at high temperatures}

Figure 5 shows typical stress-strain diagrams of UT composites at room temperature and high temperature. The UT composite tested at room temperature exhibits a typical diagram that resembles those of previously reported composites reinforced with the same woven fabrics, in which there are three stages: 1) elastic deformation through matrix stress transfer, 2) crimps of fabrics extension, and 3) yarn extension. The result showed that Young's modulus of $1.67 \mathrm{GPa}$ and tensile strength of $75.9 \mathrm{MPa}$ at room temperature. Tensile strengths at 100, 115

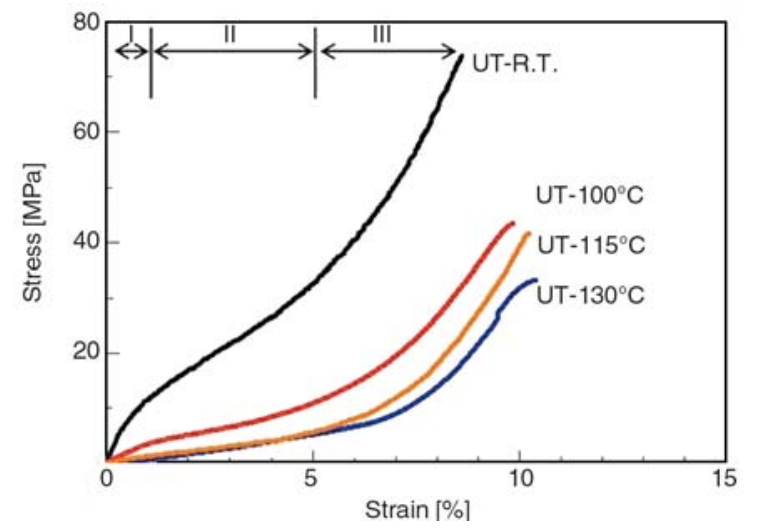

Figure 5. Typical stress-strain diagrams of UT composites at room temperature and elevated temperatures and $130^{\circ} \mathrm{C}$ are clearly less than those tested at room temperature. Furthermore, regarding their initial behavior, the deformation resistance does not appear at 115 and $130^{\circ} \mathrm{C}$ because the resin cannot transfer its shear stress to the fibers at high temperatures. As inferred from these results, plastic processing of the composite laminates might be possible at $115-130^{\circ} \mathrm{C}$.

Tensile properties of single fibers at R.T., 100, 130, 160 and $200^{\circ} \mathrm{C}$ are shown in Table 3. Tensile strength decreases greatly at $100-130^{\circ} \mathrm{C}$; it does not change so much at temperatures higher than $130^{\circ} \mathrm{C}$. Therefore, we must devote attention to such a strength decrease of the single fibers during plastic processing of the composites.

\section{2. $r$-values of fully green composite laminates}

To investigate a deep drawability of fully green composite laminates, their $r$-values were investigated through a tensile test. The test temperature was selected as $115^{\circ} \mathrm{C}$ from the results described above. Table 4 shows deformability and $r$-values of the composite laminates. In this experiment, testing was stopped at the tensile strain of $25 \%$ for the specimens, showing that the fracture strain was greater than $25 \%$. As shown in the Table 4, the $r$-value of the green composites at $115^{\circ} \mathrm{C}$ is 8.42 , which is much higher than the value range of approximately $0.7-2.1$, as indicated in sheet metals. On the other hand, although the AT composites and $\pm 45^{\circ}$ composites show larger longitudinal strains [8], their $r$-values are lower than those of the others. Especially, it is noteworthy that the $r$-value of $\pm 45^{\circ}$ composites is negative. Therefore, a more trans-

Table3. Tensile properties of single fibers

\begin{tabular}{|c|c|c|c|c|}
\hline & Fiber diameter $[\boldsymbol{\mu m}]$ & Young's modulus [GPa] & Tensile strength [MPa] & Fracture strain [\%] \\
\hline R.T. & 33.6 & 24.0 & 494 & 2.57 \\
\hline $100^{\circ} \mathrm{C}$ & 26.7 & 22.6 & 448 & 2.25 \\
\hline $130^{\circ} \mathrm{C}$ & 39.6 & 17.7 & 268 & 2.10 \\
\hline $160^{\circ} \mathrm{C}$ & 36.9 & 21.7 & 291 & 1.74 \\
\hline $200^{\circ} \mathrm{C}$ & 29.8 & 18.9 & 307 & 1.82 \\
\hline
\end{tabular}

Table 4. Deformability and $r$-values of the green composite laminates at $115^{\circ} \mathrm{C}$

\begin{tabular}{|l|c|c|c|}
\hline & Longitudinal strain [\%] & Transverse strain [\%] & $r$-value \\
\hline $\mathrm{UT}-115^{\circ} \mathrm{C}$ & 5.79 & -4.90 & 8.42 \\
\hline $\mathrm{UT}-45^{\circ}-115^{\circ} \mathrm{C}$ & 7.31 & 12.0 & -2.60 \\
\hline $\mathrm{AT}-115^{\circ} \mathrm{C}$ & 15.6 & -4.65 & 0.43 \\
\hline $\mathrm{GFRP}$ & 2.0 & - & 0.01 \\
\hline
\end{tabular}


verse compressive strain occurred than with a longitudinal tensile strain. In Table 4, the result for the AT $-115^{\circ} \mathrm{C}$ composite is also shown. In this composite, a large increase in the fracture strain at the longitudinal direction is obtained. Consequently, the $r$-value of the composite decreases compared to that of UT- $115^{\circ} \mathrm{C}$. The $r$-value of GFRP using a plane fabric at $0-90^{\circ}$ direction is 0.01 [13]. Therefore the green composite laminates used here are superior to GFRP from the perspective of plastic processing.

\subsection{Results of deep drawing}

Deep drawing processing was applied for the green composite laminates. Figures $6 \mathrm{a}$ and $6 \mathrm{~b}$ depict typical deep drawing products. Table 5 shows the classification of deep drawability by cylindrical and square punches. When alkali-treated woven fabrics are used as reinforcement, the product can achieve $20 \mathrm{~mm}$ depth for both punches. For untreated woven fabrics, the drawing was only $10 \mathrm{~mm}$ for the cylindrical punch; it was not achieved for the square punch. Figures $6 \mathrm{a}$ and $6 \mathrm{~b}$ show that about 1 and $2 \mathrm{~mm}$ wrinkles in height, respectively, were brought into UT and AT composites along the diagonal direction. As described earlier, the negative $r$-value of $\pm 45^{\circ}$ composite means that the deformation along the transverse direction is greater than the longitudinal deformation. Therefore, the wrinkle pattern is brought into the products. To reduce wrinkles in the products, the $0-90^{\circ}$ direction of AT composite was placed in the diagonal direction. Then the process was applied in the same condition. As depicted in Figure 6c, the result shows that the wrinkle pattern disappears clearly. The reason is that contraction force at the circumferential direction becomes small due to the short distance between punch and square metal frame, as compared to Figure 6a.

The results described above demonstrate that the fully green composites can produce stronger and stiffer deep drawing products than usual polymeric materials.
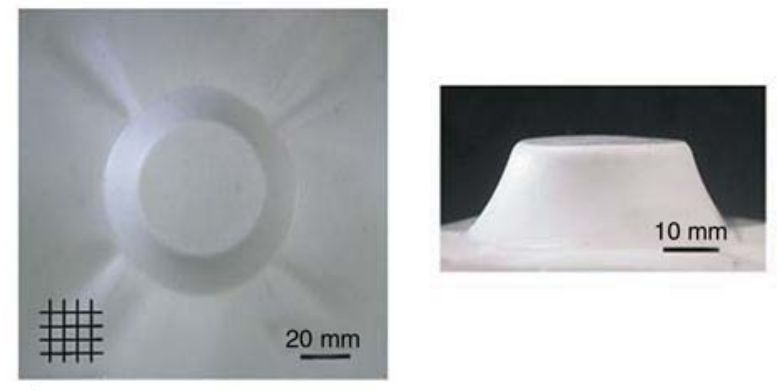

a)

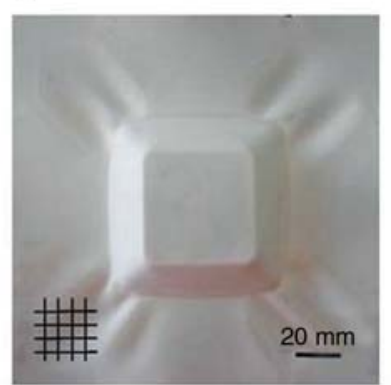

b)

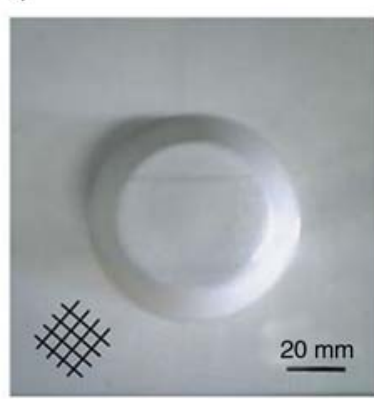

c)

Figure 6. Photographs of deep drawn products using AT composite (a) 0-90\% $/ 0-90 \% / 0-90^{\circ}$ laminate processed using a cylindrical punch,

(b) $0-90 \%-90 \%-90^{\circ}$ laminate processed using a square punch, and (c) $\pm 45^{\circ} / \pm 45^{\circ} / \pm 45^{\circ}$ laminate processed using a cylindrical punch

\section{Conclusions}

High-temperature tensile properties and deep drawability of fully green composites reinforced with ramie woven fabrics were explored. Based on the initial deformation resistance at high temperatures of the composites and high temperature tensile strength of the single fibers, it was concluded that the optimum temperature range of plastic processing for the composites was $100-115^{\circ} \mathrm{C}$.

Table 5. Classification of deep drawability

\begin{tabular}{|c|c|c|c|c|}
\hline \multirow{2}{*}{ Depth } & \multicolumn{2}{|c|}{ AT composite } & \multicolumn{2}{|c|}{ UT composite } \\
\hline & Cylindrical punch & Squared punch & Cylindrical punch & Squared punch \\
\hline $10 \mathrm{~mm}$ & $\mathrm{o}$ & o & $\mathrm{o}$ & - \\
\hline $20 \mathrm{~mm}$ & $\mathrm{o}$ & $\mathrm{o}$ & $x$ & $x$ \\
\hline
\end{tabular}

o; possible, $\times$; not possible 
Deep drawing of the composite laminates was carried out at $115^{\circ} \mathrm{C}$ using cylindrical and square punches. The results show that, when alkali-treated ramie woven fabrics were used as reinforcement, deep drawing was achieved at the depth of $20 \mathrm{~mm}$. Consequently, the development of plastic processing such as deep drawing for the green composites is expected.

\section{Acknowledgements}

The authors wish to acknowledge the Research Fellowship of the Japan Society for the Promotion of Science (JSPS) for Young Scientists for supporting this research.

\section{References}

[1] Luo S., Netravali A. N.: Interfacial and mechanical properties of environment-friendly 'green' composites made from pineapple fibers and poly (hydroxybutyrate-co-valerate) resin. Journal of Material Science, 34, 3709-3719 (1999). DOI: 10.1023/A:1004659507231

[2] Wambua P., Ivens J., Verpoest I.: Natural fibers: Can they replace glass in fibre reinforced plastics? Composites Science and Technology, 63, 1259-1264 (2003).

DOI: $10.1016 / \mathrm{S} 0266-3538(03) 00096-4$

[3] Netravali A. N., Chabba S.: Composites get greener. Materials Today, 6, 22-29 (2003).

DOI: $10.1016 /$ S1369-7021(03)00427-9

[4] Bledzki A. K., Gassan J.: Composites reinforced with cellulose based fibers. Progress in Polymer Science, 24, 221-274 (1999). DOI: $\underline{10.1016 / \mathrm{S} 0079-6700(98) 00018-5}$
[5] Goda K., Cao Y.: Research and development of fully green composites reinforced with natural fibers. Jounal of Solid Mechanics and Materials Engineering, 1, 1073-1084 (2007).

DOI: $10.1299 / \mathrm{jmmp} .1 .1073$

[6] Inoh T.: Industrial products of plant origin materialeffective use of plastics for recycling society (in Japanese). Journal of the Japan Society of Mechanical Engineers, 109, 51-52 (2006).

[7] Iji M., Serizawa S., Inoue K.: Development of polylactic acid with kenaf and its application to electronic products (in Japanese). Journal of the Japan Society of Polymer Processing, 15, 602-604 (2003).

[8] Nakamura R., Sreekala M. S., Jyouyou H., Goda K.: Creation of plasticity in textile green composites using ramie woven fabrics. International Journal of Plastics Technology, 9, 406-415 (2005).

[9] Nakamura R., Sreekala M. S., Goda K., Jyouyou H.: Plastic deformation behavior of textile green composites using a plain woven ramie fabric. in 'Proceedings of $12^{\text {th }}$ European Conference on Composite Materials, Biarritz, France' 432-434 (2006).

[10] Lankford W. T., Snyder S. C., Bauscher I. A.: New criteria for predicting the press performance of deep drawing sheet. Transactions of the American Society for Metals, 42, 1197-1232 (1950).

[11] Goda K., Sreekala M. S., Gomes A., Kaji T., Ohgi J.: Improvement of plant based natural fibers for toughening green composites -Effect of load application during mercerization of ramie fibers. Composites Part A, 37, 2213-2220 (2006).

DOI: $10.1016 /$ j.compositesa.2005.12.014

[12] Sao K. P., Samantray B. K., Bhattacherjee S.: X-ray study and disorder in ramie fiber. Journal of Applied Polymer Science, 52, 1687-1694 (1994). DOI: 10.1002/app.1994.070521203

[13] Omura M., Okamoto K.: Relation between plastic workability and fraction of fibers on GFRP sheet (in Japanese). Journal of the Society of Material Science, Japan, 47, 452-457 (1998). 